Check for updates

Cite this: RSC Adv., 2017, 7, 55577

Received 12th October 2017

Accepted 2nd December 2017

DOI: $10.1039 / c 7 r a 11228 a$

rsc.li/rsc-advances

\section{An acidic pH fluorescent probe based on Tröger's base}

\begin{abstract}
Chunxue Yuan, (D) *ab Yanmin Zhang, ${ }^{\mathrm{a}} \mathrm{He} \mathrm{Xi}{ }^{\mathrm{C}}{ }^{\mathrm{c}}$ and Xutang Tao (D) ${ }^{\mathrm{b}}$
A novel pH fluorescent probe 2,8- $(6 \mathrm{H}, 12 \mathrm{H}-5,11$-methanodibenzo[ $b, f]$ diazocineylene)-di( $p$-ethenylpyridine) (TBPP) incorporating an electron-donating amine moiety and electron-accepting pyridine group through Tröger's base linker was designed and synthesized. TBPP exhibits an intramolecular charge transfer effect caused by the donor-acceptor interaction between its amine and pyridine units. Its emission can be reversibly switched between blue and dark states by protonation and deprotonation. Such behavior enables it to work as a turn-off fluorescent $\mathrm{pH}$ sensor in solution state. ${ }^{1} \mathrm{H}$ NMR spectroscopy analysis suggests that the change in electron affinity of the pyridinyl unit upon protonation and deprotonation is responsible for such sensing processes.
\end{abstract}

\section{Introduction}

$\mathrm{pH}$ is a key parameter in a wide range of fields such as environmental analysis, chemical process control, food production, medical diagnosis and life science. ${ }^{\mathbf{1 - 6}}$ Many important physiological processes of cells and organelles are also related to $\mathrm{pH}$ values. $^{7,8}$ Consequently, the measurement of $\mathrm{pH}$ is of great importance in the field of environmental, chemical, medical and life sciences. Many techniques have been used for measuring $\mathrm{pH}$ value including UV-vis absorbance spectroscopy, ${ }^{\mathbf{9}, 10}$ fluorescence spectroscopy, ${ }^{\mathbf{1 1}, \mathbf{1 2}}$ nuclear magnetic resonance ${ }^{13,14}$ and electrochemistry. ${ }^{15,16}$ Among these methods, fluorescent probes for $\mathrm{pH}$ detection have attracted much more attention due to their convenient operation, particularly high sensitivity, non-invasiveness and real-time detection. ${ }^{17}$ Towards this end, many kinds of $\mathrm{pH}$ fluorescent probes have been explored including fluoresceins, ${ }^{18,19}$ coumarins $^{20,21}$ and rhodamines ${ }^{22,23}$ etc. However, most reported fluorescence $\mathrm{pH}$ probes are practical for near-neutral $\mathrm{pH}$ range while there are limited probes for monitoring $\mathrm{pH}$ changes in acidic organelles. And some $\mathrm{pH}$ probes still suffer from the severe excitation interference caused by a shorter Stokes shift. There is a great pressing need to develop fluorescent probes toward high sensitivity and large Stokes shift for monitoring acid physiological $\mathrm{pH}$ fluctuations.

Tröger's base (TB), ${ }^{24}$ first synthesized in 1887, has gained steady interest in recent years because of its $C 2$ symmetry, chirality, and rigid concave shape..$^{25,26}$ Our recent work indicated

${ }^{a}$ College of Materials Science and Engineering, Tongji University, Caoan Road 4800, Shanghai 201804, P. R. China.E-mail: cxyuan@tongji.edu.cn

${ }^{b}$ State Key Laboratory of Crystal Materials, Shandong University, Shanda South Road 27, Jinan, 250100, P. R. China

${ }^{c}$ School of Advanced Materials and Nanotechnology, Xidian University, South Taibai Road 2, Xi'an 710071, P. R. China pyridinium salts based on TB display a special aggregationinduced emission (AIE) property that it is non-emissive in solution but exhibit strong fluorescence in solid state. ${ }^{27,28}$ In addition, N-heterocyclic derivatives are ideal substances for use as hydronium ion indicators owing to the high sensitivity and the exceptionally rapid rates of proto transfer occurring in acidbase equilibrium process. ${ }^{\mathbf{1 1 , 2 9 , 3 0}}$ With this in mind, we designed and synthesized a new compound TBPP based on TB by introducing the pyridine electron-withdrawing group into TB framework. We expect that optical change could be achieved through the transformation between the neutral TBPP and nonfluorescence ionic pyridinium salt by protonation. Proton titration experiments indicated that TBPP can be used as a turnoff $\mathrm{pH}$ fluorescent probe for acidic $\mathrm{pH}$ detection with high sensitivity.

\section{Experimental section}

\section{Materials and instrumentation}

All commercially available chemicals were purchased from Adamas, Aldrich and TCI, and used as received without further purification except $N$-methyl pyrrolidone was dried over $3 \AA$ molecular sieves. 2,8-Dibromo-6H,12H-5,11-methanodibenzo $[b, f][1,5]$ diazocine was prepared according to literature procedures. $^{31}$

${ }^{1} \mathrm{H}$ and ${ }^{13} \mathrm{C}$ NMR spectra were recorded on a Bruker AVANCE 400 spectrometer. The chemical shifts are reported in $\delta \mathrm{ppm}$ with reference to residual protons and carbons of $\mathrm{CDCl}_{3}$ (7.26 ppm in ${ }^{1} \mathrm{H}$ NMR and $77.16 \mathrm{ppm}$ in ${ }^{13} \mathrm{C}$ NMR) and DMSO- $d_{6}$ (2.50 ppm in ${ }^{1} \mathrm{H}$ NMR and $39.52 \mathrm{ppm}$ in ${ }^{13} \mathrm{C} \mathrm{NMR}$ ). Coupling constants $J$ are given in hertz. Mass spectra was measured with a Bruker Daltonics micrOTOF-focus using the APCI-TOF method in the positive-ion mode in toluene. The UV-visible absorption spectra were measured on a TU-1800 
spectrophotometer using a quartz cuvette having $1 \mathrm{~cm}$ path length. The photoluminescence spectra were collected on a Hitachi F-4500 fluorescence spectrophotometer with a $150 \mathrm{~W}$ Xe lamp. Fluorescence quantum yields $(\Phi)$ were determined using quinine sulfate in $0.1 \mathrm{~N}$ sulfuric acid $(\Phi=0.577)$ as standard.

Solvents were purified and dried according to standard procedures. Thin layer chromatography (TLC) was performed on glass plates coated with $0.20 \mathrm{~mm}$ thickness of silica gel. Column chromatography was performed using neutral silica gel PSQ100B.

\section{General procedure for spectroscopic measurements}

Stock solution of probe with a concentration of $1.0 \mathrm{mM}$ was prepared in DMSO and the solution for spectroscopic determination was obtained by diluting the stock solution to $10.0 \mu \mathrm{M}$ in DMSO. The metal ions were provided by $\mathrm{NaCl}, \mathrm{KCl}, \mathrm{CaCl}_{2}$, $\mathrm{MgCl}_{2}, \mathrm{CuCl}_{2} \cdot 2 \mathrm{H}_{2} \mathrm{O}, \mathrm{MnCl}_{2}, \mathrm{CoCl}_{2} \cdot 6 \mathrm{H}_{2} \mathrm{O}, \mathrm{Ni}\left(\mathrm{NO}_{3}\right)_{2} \cdot 6 \mathrm{H}_{2} \mathrm{O}$, $\mathrm{Cd}\left(\mathrm{NO}_{3}\right)_{2} \cdot 4 \mathrm{H}_{2} \mathrm{O}, \mathrm{AlCl}_{3}, \mathrm{Zn}\left(\mathrm{NO}_{3}\right)_{2} \cdot 6 \mathrm{H}_{2} \mathrm{O}, \mathrm{Cr}\left(\mathrm{NO}_{3}\right)_{2} \cdot 9 \mathrm{H}_{2} \mathrm{O}$. In the $\mathrm{pH}$ titrations experiments, the slight $\mathrm{pH}$ variations of the solutions were achieved by adding the minimum volumes of $\mathrm{HCl}$ (1.0 mM). Spectral data were recorded after each addition. The excitation wavelength was $340 \mathrm{~nm}$. The resulting solution was shaken well and kept at room temperature for $30 \mathrm{~min}$ before taking its absorption and fluorescence spectra.

\section{Synthesis of $2,8-(6 H, 12 H-5,11-$ methanodibenzo $[b, f]$ diazocineylene)-di( $p$-ethenyl- $N$-pyridine) (TBPP)}

To a stirring of 2,8-dibromo- $6 H, 12 H$-5,11-methanodibenzo[ $b, f]$ [1,5]diazocine (5.0 mmol, $1.9 \mathrm{~g}$ ), 4-vinyl pyridine $(20.0 \mathrm{mmol}$, $2.2 \mathrm{~mL}$ ) and $\mathrm{K}_{2} \mathrm{CO}_{3}(20.0 \mathrm{mmol}, 2.8 \mathrm{~g}$ ) in $\mathrm{N}$-methyl pyrrolidone $(10 \mathrm{~mL})$ was added tris(2-methylphenyl)phosphine $(0.001 \mathrm{mmol}, 0.003 \mathrm{~g})$ and palladium acetate $(0.001 \mathrm{mmol}$, $0.0023 \mathrm{~g}$ ) as catalysts. The mixture was stirred at $130{ }^{\circ} \mathrm{C}$ for $10 \mathrm{~h}$ under $\mathrm{N}_{2}$ atmosphere and monitored by TLC. After the reaction was finished, the reaction mixture was cooled to room temperature and extracted by $\mathrm{CH}_{2} \mathrm{Cl}_{2}$ for three times. Combined organic phase was washed with water for three times and dried over anhydrous $\mathrm{MgSO}_{4}$. After evaporation of the solvent, the mixture was purified by a silica gel column chromatography (eluent: $\mathrm{CH}_{2} \mathrm{Cl}_{2}$ /ethanol $=40 / 1$ in the ratio of volume) to afford TBPP (1.22 g, $2.85 \mathrm{mmol})$ in 57\% yield as a light yellow solid. Mp: $287.01{ }^{\circ} \mathrm{C} .{ }^{1} \mathrm{H}$ NMR $\left(300 \mathrm{MHz}, \mathrm{CDCl}_{3}\right), \delta(\mathrm{ppm}): 4.23(\mathrm{~d}, 2 \mathrm{H}$, $J=16.5 \mathrm{~Hz}), 4.35(\mathrm{~s}, 2 \mathrm{H}), 4.74(\mathrm{~d}, 2 \mathrm{H}, J=16.8 \mathrm{~Hz}), 6.86(\mathrm{~d}, 2 \mathrm{H}, J$ $=16.2 \mathrm{~Hz}), 7.09-7.19(\mathrm{~m}, 6 \mathrm{H}), 7.26-7.30(\mathrm{~m}, 4 \mathrm{H}), 7.35-7.39(\mathrm{dd}$, $2 \mathrm{H}, J=8.4 \mathrm{~Hz}), 8.53(\mathrm{~d}, 4 \mathrm{H}, J=6.0 \mathrm{~Hz}) .{ }^{13} \mathrm{C} \mathrm{NMR}(75.47 \mathrm{MHz}$, $\left.\mathrm{CDCl}_{3}\right), \delta$ (ppm): 58.72, 66.91, 120.69, 125.08, 125.43, 125.75, 126.09, 128.13, 132.11, 132.51, 144.65, 148.71, 150.11. HR-MS (APCI, positive): $\left[(\mathrm{M}+\mathrm{H})^{+}\right]$calcd for $\mathrm{C}_{29} \mathrm{H}_{24} \mathrm{~N}_{4}, 429.2074$; found 429.2461 .

\section{Results and discussion}

\section{Synthesis}

As outlined in Scheme 1, compound TBPP was synthesized in moderate yield directly by Heck coupling reaction of 4-vinyl

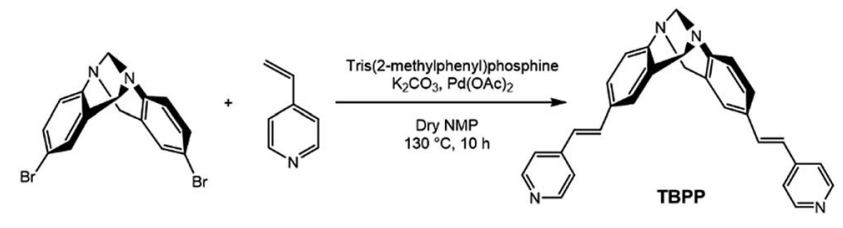

Scheme 1 Synthesis of probe TBPP

pyridine with 2,8-dibromo- $6 H, 12 H-5,11$-methanodibenzo[ $b, f]$ $[1,5]$ diazocine in the presence of a base and palladium catalyst.

The product was characterized by ${ }^{1} \mathrm{H}$ NMR, ${ }^{13} \mathrm{C}$ NMR and HRMS methods. It is readily soluble in normal solvents such as benzene, $\mathrm{CH}_{2} \mathrm{Cl}_{2}, \mathrm{CHCl}_{3}$, THF, methanol, ethanol, $\mathrm{CH}_{3} \mathrm{CN}$, DMF, DMSO, but insoluble in hexane and water.

\section{Photophysical properties of probe TBPP}

In our experiment, we found that both of solutions and solids of TBPP show strong blue emissions (the photos were shown in the inset of Fig. 1(a)). The normalized absorption and fluorescence
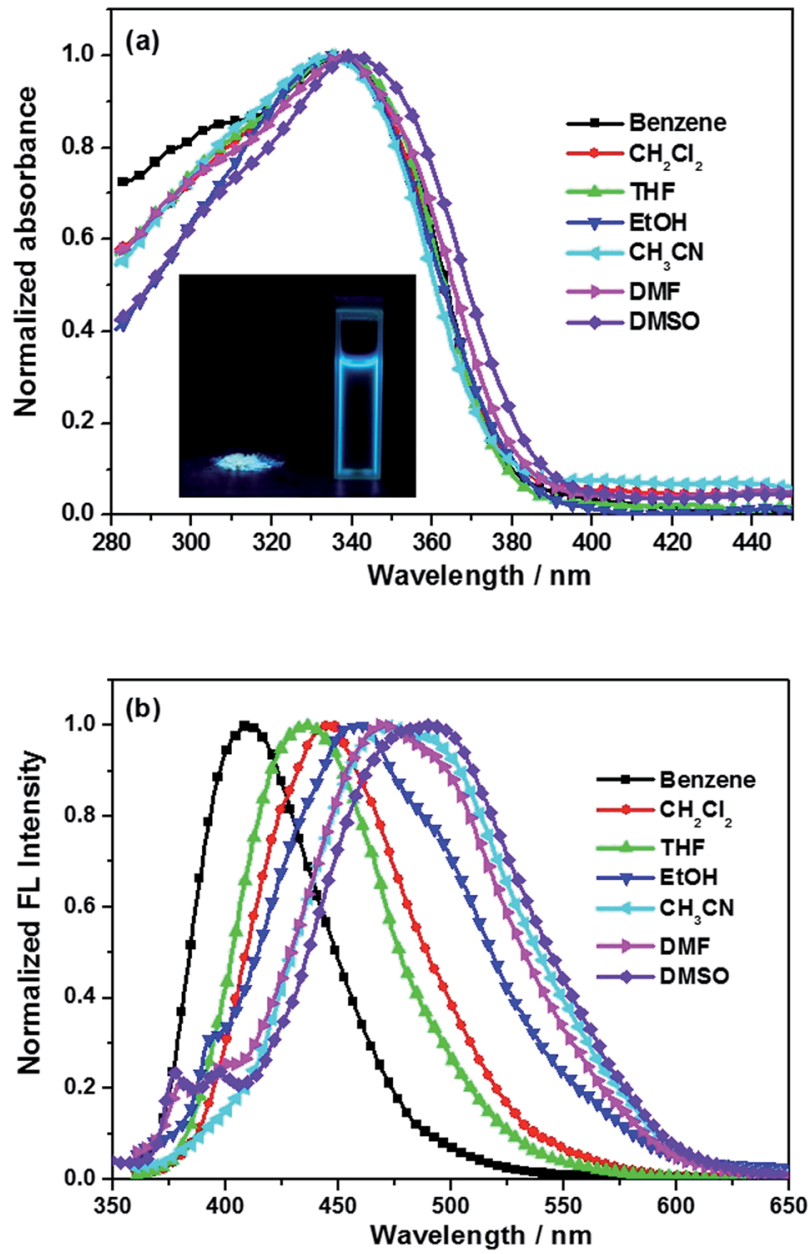

Fig. 1 Normalized (a) UV and (b) PL spectra of TBPP in solvents with different polarities. The inset shown the photos of the solutions and solids of TBPP under illumination. The excitation wavelength is $336 \mathrm{~nm}$. 
Table 1 Photophysical properties of TBPP

\begin{tabular}{lllll}
\hline Solvent & $\lambda_{\text {abs }}{ }^{a}(\mathrm{~nm})$ & $\lambda_{\mathrm{F}}{ }^{b}(\mathrm{~nm})$ & $\Delta \lambda$ & $\Phi_{\mathrm{F}}{ }^{c}$ \\
\hline Benzene & 335 & 409 & 74 & 0.74 \\
$\mathrm{CH}_{2} \mathrm{Cl}_{2}$ & 337 & 445 & 108 & 0.94 \\
THF & 337 & 435 & 98 & 1.62 \\
Ethanol & 336 & 458 & 122 & 0.14 \\
$\mathrm{CH}_{3} \mathrm{CN}$ & 336 & 473 & 137 & 0.50 \\
DMF & 337 & 472 & 135 & 0.94 \\
DMSO & 340 & 489 & 149 & 0.69
\end{tabular}

${ }^{a}$ Peak wavelength of absorption spectrum. ${ }^{b}$ Peak wavelength of fluorescence spectrum. ${ }^{c}$ Quantum yield determined using quinine sulfate as the standard.

emission spectra of TBPP in various solvents with different polarity were shown in Fig. 1. The absorption peak wavelength, fluorescence peak wavelength, Stokes' shift and fluorescence quantum yields were summarized in Table 1 . Increase the polarity of solvent (benzene, $\mathrm{CH}_{2} \mathrm{Cl}_{2}$, THF, ethanol, acetonitrile, DMF, DMSO), no obvious spectral shift was observed in the absorption spectra with the absorption peaks locate at the range from 335 to $340 \mathrm{~nm}$ while fluorescence spectra shown a large red-shift that the fluorescence peaks changed from 409 to $489 \mathrm{~nm}$. The Stokes' shift is changed from $74 \mathrm{~nm}$ to $149 \mathrm{~nm}$. This can be explained by the fact that the excited state of the compound TBPP may possess higher polarity than that of the ground state. For the solvatochromism is associated with the energy level lowering. Increased dipole-dipole interaction between the solute and solvent leads to lowering the energy level greatly. ${ }^{32,33}$ The amine on TB bridge and pyridine group act as electron donor and acceptor, respectively. Each wing of compound TBPP is a $\mathrm{D}-\pi-\mathrm{A}$ charge transfer structure. Therefore, the intense fluorescence of TBPP in solution and solid state should contributed from the effective intramolecular charge transfer (ICT) through strong push-pull interaction between the electron-donor amine moiety on TB bridge and the electron-acceptor pyridine group.

\section{pH titrations of probe TBPP}

To study the optical responses of probe TBPP to $\mathrm{pH}, \mathrm{pH}$ titrations of absorption spectra and fluorescence emission spectra were performed. As shown in Fig. 2(a), along with the $\mathrm{H}^{+}$ addition, the original absorption band at $340 \mathrm{~nm}$ decreased and a new band around $390 \mathrm{~nm}$ increased gradually. A well-defined isosbestic point at $356 \mathrm{~nm}$ was observed. A notable color change from colorless to yellow (the inset in Fig. 2(a)) was observed upon increasing the acidity. Therefore, this probe can serve as a "naked-eye" colorimetric indicator for acidic $\mathrm{pH}$.

The fluorescence property of TBPP as a function of $\mathrm{pH}$ were displayed in Fig. 2(b) and (c). Before the addition of acid, DMSO solution of TBPP exhibited an intense emission band around $490 \mathrm{~nm}$ with a large Stokes shift of $149 \mathrm{~nm} .^{\mathbf{2 9 , 3 0 , 3 4 , 3 5}}$ The large Stokes shift should help to reduce the excitation interference. Upon increasing the amount of $\mathrm{H}^{+}$, the fluorescence intensity reduced gradually until quenched completely. The fluorescence
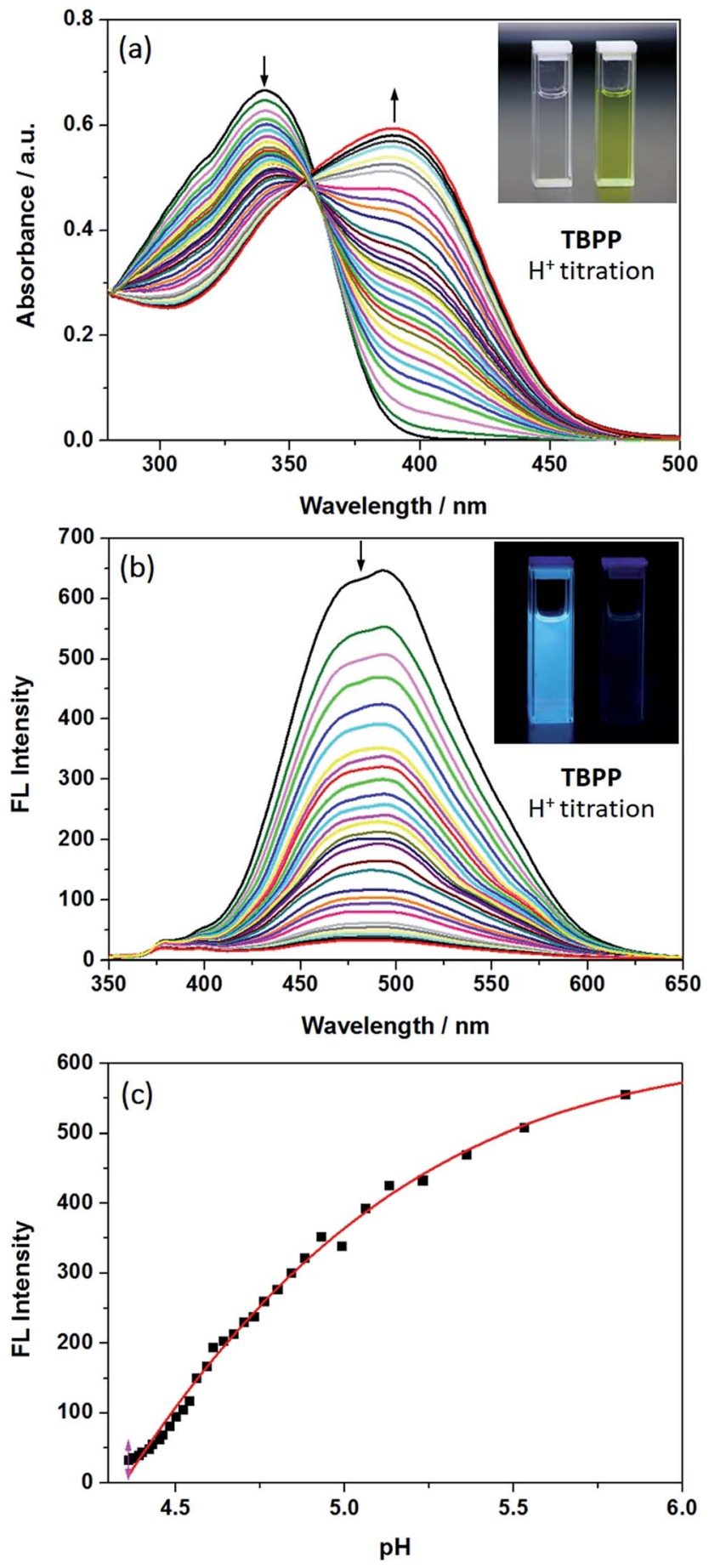

Fig. 2 (a) UV-vis absorption and (b) PL spectra of TBPP in DMSO with different $\mathrm{pH}$ value. (c) Plots of FL peak intensities of TBPP vs. $\mathrm{pH}$ value. The excitation wavelength is $340 \mathrm{~nm}$. Insert: photos of TBPP under natural light and UV lamp (365 nm) before and after the titration.

change was well demonstrated in the fluorescence photos which were shown in the inset of Fig. 2(b). It is should be noted that there was no spectral shift was observed during the titration experiments. This means the new species resulted from the protonation of $\mathrm{N}$ atoms in pyridine group is non-emissive in solution state. This property of $\mathbf{T B P P}-\mathbf{H}^{+}$is similar to our previous pyridinium salts. ${ }^{27,28}$ The fluorescence color change 

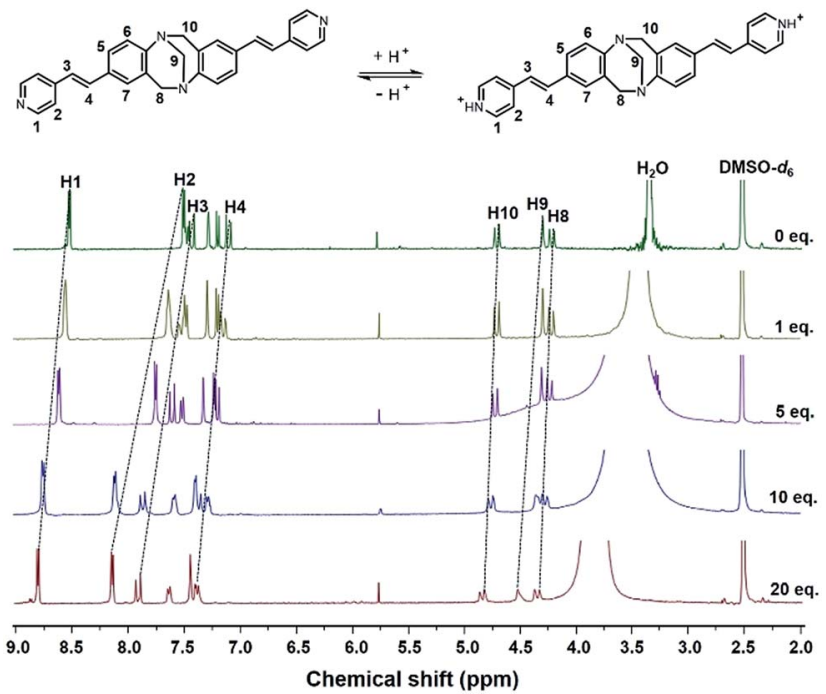

Fig. $3{ }^{1} \mathrm{H}$ NMR spectra of probe TBPP in DMSO- $d_{6}$ and probe with different equivalent hydrochloric acid.

was due to the protonation of $\mathrm{N}$ atoms in pyridine group. Under strongly acid condition, the protonation of $\mathrm{N}$ atoms in pyridine group enhanced their electron withdrawing ability, which resulted in the of ICT effect from pyridine group to amine group. The structures of TBPP, TBPP- $\mathbf{H}^{+}$and the sensing process were depicted in Fig. 3. The UV-vis absorption and corresponding fluorescence emission properties during the $\mathrm{pH}$ titrations enable probe TBPP to serve as a highly sensitive probe for precisely $\mathrm{pH}$ measuring in acidic regions through colorimetric and fluorimetric changes.

\section{Proposed mechanism}

To study the proton-binding behavior, the ${ }^{1} \mathrm{H}$ NMR spectroscopy of probe TBPP in DMSO- $\mathrm{d}_{6}$ with different equivalent hydrochloric acid has been acquired. As illustrated in Fig. 3, with the addition of incremental amounts of $\mathrm{HCl}$ to TBPP solution in DMSO- $d_{6}$, the pyridine proton signals ( $\mathrm{H} 1$ and $\mathrm{H} 2$ ) were gradually shifted down-field because of the transformation of the pyridine ring in TBPP to an electron-deficient pyridinium unit in TBPP- $\mathbf{H}^{+}$. The resonances of phenyl and vinyl protons (H3 and H4) also move to lower fields for the same reason. However, the chemical shifts of amine protons had almost no change (H8, H9 and H10), which indicated that the protonation occurred at the pyridine $\mathrm{N}$ rather than amine $\mathrm{N}$. The downfield chemical shift of these protons was obviously due to $\mathrm{H}^{+}$binding with $\mathrm{N}$ atom of pyridine, which resulted in the decrease of electron density around these protons. The presence of acid-base equilibrium between the two forms of TBPP was given in Scheme 2 .

\section{Selectivity of probe TBPP}

The selectivity response of probe to $\mathrm{H}^{+}$over various metal ions were examined at pH 5.83 and 4.10, respectively. It is noteworthy that TBPP shows high selectivity toward $\mathrm{H}^{+}$. As shown in Fig. 4, physiologically ubiquitous metal ions including $\mathrm{Na}^{+}, \mathrm{K}^{+}, \mathrm{Mg}^{2+}$ and $\mathrm{Ca}^{2+}$, as well as other heavy and transition metal ions, such

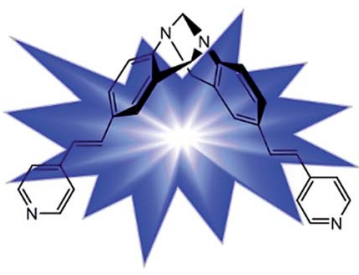

TBPP

Non-fluorescence

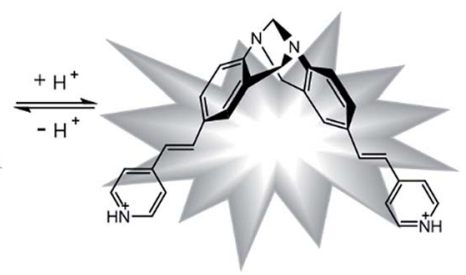

TBPP-H

Strong fluorescence
Scheme $2 \mathrm{pH}$-Dependent equilibrium of probe TBPP.

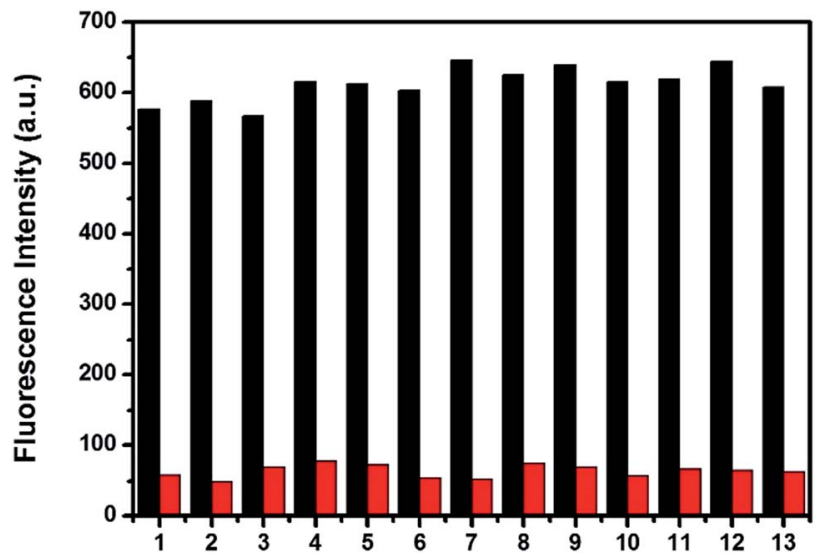

Fig. 4 Fluorescence responses $(490 \mathrm{~nm})$ of TBPP $(10.0 \mu \mathrm{M})$ in DMSO solutions at $\mathrm{pH} 5.83$ (black bars) and 4.10 (red bars) in the presence of diverse metal ions. (1) Blank; (2) $\mathrm{Na}^{+}(150 \mathrm{mM}) ;(3) \mathrm{K}^{+}(150 \mathrm{mM}) ;(4) \mathrm{Ca}^{2+}$ $(10 \mathrm{mM}) ;(5) \mathrm{Mg}^{2+}(2 \mathrm{mM}) ;(6) \mathrm{Cu}^{2+}(0.2 \mathrm{mM}) ;(7) \mathrm{Mn}^{2+}(0.2 \mathrm{mM}) ;(8)$ $\mathrm{Co}^{2+}(0.2 \mathrm{mM})$; (9) $\mathrm{Ni}^{2+}(0.2 \mathrm{mM}) ;(10) \mathrm{Cd}^{2+}(0.2 \mathrm{mM}) ;(11) \mathrm{Al}^{3+}$ $(0.2 \mathrm{mM})$; (12) $\mathrm{Zn}^{2+}(0.2 \mathrm{mM})$; (13) $\mathrm{Cr}^{3+}(0.2 \mathrm{mM})$; the excitation wavelength is $340 \mathrm{~nm}$.

as $\mathrm{Cu}^{2+}, \mathrm{Mn}^{2+}, \mathrm{Co}^{2+}, \mathrm{Ni}^{2+}, \mathrm{Cd}^{2+}, \mathrm{Al}^{3+}, \mathrm{Zn}^{2+}$ and $\mathrm{Cr}^{3+}$ caused no visible effect on the fluorescence intensity of the probe at $\mathrm{pH}$ 5.83 and 4.10. These results revealed that TBPP showed an excellent selectivity response to $\mathrm{H}^{+}$in the presence of metal ions.

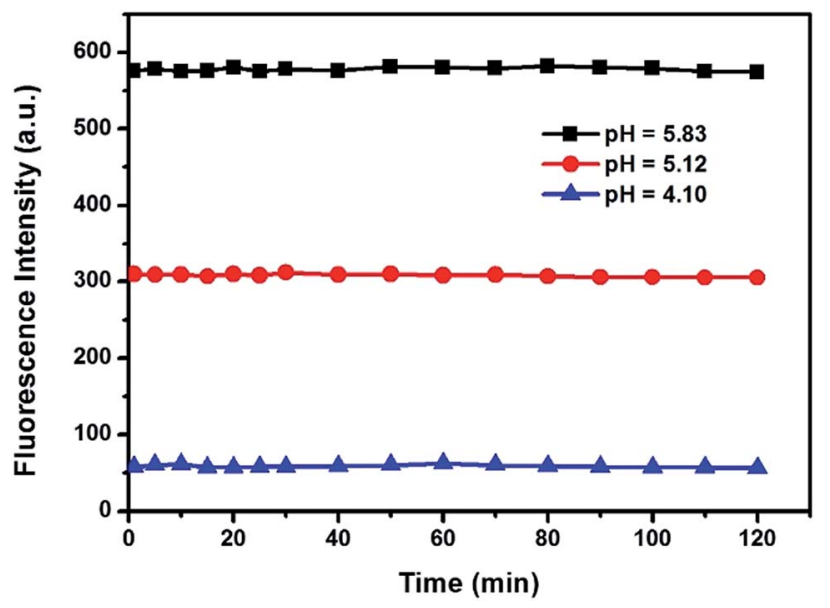

Fig. 5 Changes in the fluorescence intensity at $490 \mathrm{~nm}$ for TBPP $(10.0 \mu \mathrm{M})$ in DMSO solutions with times at $\mathrm{pH} 5.83,5.12$ and 4.10, respectively. 


\section{Photostability of probe TBPP}

The stability of the probe was tested by measuring the fluorescent response during $2 \mathrm{~h}$ with $\mathrm{pH} 5.83,5.12$, and 4.10, respectively (Fig. 5). The fluorescence intensity was continuously monitored and recorded at set time intervals at $490 \mathrm{~nm}$. The results indicated that the probe can instantly respond to the change of $\mathrm{H}^{+}$concentration, and the probe solution is stable. Thus, the probe can be used to monitor the $\mathrm{pH}$ variation in real time.

\section{Conclusion}

In summary, we have designed and synthesized a new $\mathrm{pH}$ fluorescent probe TBPP based on TB by introducing the pyridine electron-withdrawing group into TB framework. The UV-vis absorption and fluorescence titrations indicated that TBPP can serve as a highly sensitive probe for $\mathrm{pH}$ measuring in acidic regions through colorimetric and fluorimetric changes. Furthermore, the detection mechanism has been verified by ${ }^{1} \mathrm{H}$ NMR spectroscopy. The large Stokes shift (149 nm), high sensitivity, good selectivity, and extremely short response time under extreme acidic condition of the probe makes it an extremely effective pH sensor. We believe it will be great beneficial to study chemical and biological system.

\section{Conflicts of interest}

There are no conflicts to declare.

\section{Acknowledgements}

We gratefully acknowledge the financial support from the state National Natural Science Foundation of China (Grant No. 51403157, 61704128) and the Fundamental Research Funds for the Central Universities.

\section{Notes and references}

1 Q. J. Ma, H. P. Li, F. Yang, J. Zhang, X. F. Wu, Y. Bai and X. F. Li, Sens. Actuators, B, 2012, 166, 68.

2 N. I. Georgiev, R. Bryaskova, R. Tzoneva, et al., Bioorg. Med. Chem., 2013, 21, 6292.

3 X. J. Cao, L. N. Chen, X. Zhang, et al., Anal. Chim. Acta, 2016, 920, 86.

4 X. F. Zhang, T. Zhang, S. L. Shen, et al., J. Mater. Chem., 2015, 3, 3260 .

5 W. Pan, H. Wang, L. Yang, Z. Yu, N. Li and B. Tang, Anal. Chem., 2016, 88, 6743.

6 J. H. Cheng, Y. H. Zhang, X. F. Ma, X. G. Zhou and H. F. Xiang, Chem. Commun., 2013, 49, 11791.

7 M. Chesler, Physiol. Rev., 2003, 83, 1183.
8 A. M. Paradiso, R. Y. Tsien and T. E. Machen, Nature, 1987, 325, 447.

9 R. G. Zhang, S. G. Kelsen and J. C. Lamanna, J. Appl. Physiol., 1990, 68, 1101.

10 J. Han and K. Burgess, Chem. Rev., 2010, 110, 2709.

11 J. Yin, Y. Hu and J. Yoon, Chem. Soc. Rev., 2015, 44, 4619.

12 Y. K. Yue, F. J. Huo, S. Y. Lee, C. X. Yin and J. Y. Yoon, Analyst, 2017, 142, 30.

13 S. He, R. P. Mason, S. Hunjan, V. D. Mehta, V. Arora, R. Katipally, P. V. Kulkami and P. P. Antich, Bioorg. Med. Chem., 1998, 6, 1631.

14 S. J. Hesse, G. J. Ruijter, C. Dijkema and J. Visser, J. Biotechnol., 2000, 77, 5.

15 M. J. Kiani, M. A. A. Razak, F. K. C. Harun, M. T. Ahmadi and M. Rahmani, J. Nanomater., 2015, 2015, 1.

16 J. Zhou, L. Zhang and Y. Tian, Anal. Chem., 2016, 88, 2113.

17 G. Mattock and G. R. Taylor, pH Measurement and Titration, Macmillan, Heywood, London, 1961, vol. 888, p. 31.

18 X. Xiong, F. Song, J. Wang, Y. Zhang, Y. Xue and L. Sun, J. Am. Chem. Soc., 2014, 136, 9590.

19 Y. H. Chan, C. Wu, F. Ye, Y. Jin, P. B. Smith and D. T. Chiu, Anal. Chem., 2011, 83, 1448.

20 L. Long, Y. Wu, L. Wang, A. Gong, R. Hu and C. Zhang, Anal. Chim. Acta, 2016, 908, 1.

21 M. Lee, N. G. Gubernator, D. Sulzer and D. Sames, J. Am. Chem. Soc., 2010, 132, 8828.

22 H. Zhu, J. Fan, Q. Xu, et al., Chem. Commun., 2012, 48, 11766.

23 L. B. Xu, S. G. Wei, Q. P. Diao, P. Y. Ma, X. Liu, Y. Sun, D. Q. Song and X. H. Wang, Sens. Actuators, B, 2017, 246, 395.

24 J. Tröger, J. Prakt Chem., 1887, 36, 225.

25 C. X. Yuan, Q. Xin, H. J. Liu, L. Wang, M. H. Jiang and X. T. Tao, Sci. China: Chem., 2011, 54, 587.

26 V. R. Ögmundur, A. Josep and W. Kenneth, Eur. J. Org. Chem., 2012, 7015.

27 C. X. Yuan, X. T. Tao, Y. Ren, Y. Li, J. X. Yang, W. T. Yu, L. Wang and M. H. Jiang, J. Phys. Chem. C, 2007, 111, 12811.

28 C. X. Yuan, X. T. Tao, L. Wang, J. X. Yang and M. H. Jiang, J. Phys. Chem. C, 2009, 111, 6809.

29 Z. Y. Yang, W. Qin, W. Y. Lam, S. J. Chen, H. Y. Sung, D. Williams and B. Z. Tang, Chem. Sci., 2013, 4, 3725.

30 J. B. Chao, H. J. Wang, Y. B. Zhang, C. X. Yin, F. J. Huo, K. L. Song, Z. Q. Lia, T. Zhang and Y. Q. Zhao, Talanta, 2017, 174, 468.

31 J. Jensen, M. Strozyk and K. Wärnmark, J. Heterocycl. Chem., 2003, 40, 373.

32 P. Fromherz, J. Phys. Chem., 1995, 99, 7188.

33 U. Narang, C. F. Zhao, J. D. Bhawalkar, F. V. Bright and P. N. Prasad, J. Phys. Chem., 1996, 100, 4521.

34 J. Chao, H. Wang, K. Song, Z. Li, Y. Zhang, C. Yin, F. Huo, J. Wang and T. Zhang, Tetrahedron, 2016, 72, 8342.

35 F. Miao, G. Song, Y. Sun, Y. Liu, F. Guo, W. Zhang, M. Tian and X. Yu, Biosens. Bioelectron., 2013, 50, 42. 